\title{
Crop yield after 5 decades of contrasting residue management
}

\author{
I. Piccoli · F. Sartori $\cdot$ R. Polese $\cdot$ A. Berti
}

Received: 20 August 2019/Accepted: 6 April 2020/Published online: 17 April 2020

(C) The Author(s) 2020

\begin{abstract}
The benefits of soil organic input on crop yields have long been discussed, yet details of their relationship remain controversial. This study considers the effects of different residue management on crop performance as assessed by yield and nitrogen use efficiency (NUE). Three residue management (residue removal, residue incorporation, and residue incorporation + added poultry manure), combined with five levels of $\mathrm{N}$ application, were studied in a long-term experiment starting in 1966. Crop residue incorporation improved maize yield by $12 \%$ (nutritional effect) and sugar beet yield by $16 \%$ (nonnutritional), and the combination of crop residue incorporation with added poultry manure increased both winter wheat and sugar beet yields by $8 \%$ (nutritional effect). The NUE values of mineral fertiliser were almost three-fold those of residues and the combination of residue with poultry manure, except in sugar beet and maize, where NUE of mineral fertilizer approached those observed for residues $(0.44$ vs 0.45 , on average). In wheat, NUE for residue incorporation with added poultry manure was nearly
\end{abstract}

Electronic supplementary material The online version of this article (https://doi.org/10.1007/s10705-020-10067-9) contains supplementary material, which is available to authorized users.

I. Piccoli · F. Sartori $(\bowtie) \cdot$ R. Polese $\cdot$ A. Berti DAFNAE Department, University of Padova, Viale Dell'Università 16, 35020 Legnaro, PD, Italy

e-mail: felice.sartori@phd.unipd.it double the NUE for residues alone. Residue management effects depended on crop type; spring-sown crops showing stronger effects than those sown in autumn. Residues primarily produced a nutritional effect, suggesting that they decomposed within 1 year. While residue use offers little potential for soil improvement, it does reduce the need for fertilisers.

Keywords Crop residues $\cdot$ Crop yield $\cdot$ Long-term experiment $\cdot$ Nitrogen use efficiency $\cdot$ Poultry manure
Abbreviations
SOC Soil organic carbon
SOM Soil organic matter
NUE Nitrogen use efficiency
PM Poultry manure
RR Residue removal
RI Residue incorporation
$\mathrm{N}_{\text {app }} \quad$ Applied N
$\mathrm{N}_{\text {rec }}$ Recovered N

\section{Introduction}

Researchers have worked for decades to quantify the effects of organic input on the complex of properties subsumed under the term "soil fertility" (Russell 1977). Organic input into the soil is derived mainly from endogenous factors (e.g., spontaneous plant roots, microorganisms, and exudates), but exogenous 
agronomic factors (crop roots and residues, organic fertiliser, and soil tillage) may also be key influencers. Among the latter, crop residues are often viewed as contributing little to soil organic matter (SOM) accumulation in the humid and sub-humid climates where they are readily mineralised (Kätterer et al. 2011; Berti et al. 2016; Poeplau et al. 2017). Therefore, the effects of crop residues on crop yields are considered to be primarily nutritional (supplying nutrients) (Pituello et al. 2016). Indeed, the benefits of organic input on crop yields might relate to all of the fertility dimensions: "physical" when affecting soil structure, aeration, water retention, etc.; "biological" when promoting biomass, biodiversity, nutrient mineralization, or disease suppression; "chemical" when supplying nutrients. Previously, readily-mineralisable $\mathrm{N}$ (e.g., poultry manure) was thought to enhance humification (lower $\mathrm{C}: \mathrm{N}$ ratio), and thus to suitable organic amendments (Himes 2018). However, 20 years of soil spectroscopy and scanning transmission microscopy have shown that organic matter is comprised of smaller, simpler biomolecules (Sutton and Sposito 2005; Lehmann et al. 2008; Kleber and Johnson 2010), rather than large, complex molecules (humic substances). Consequently, organic matter persistence in soil is no longer viewed as intrinsic to SOM, but rather as a property of the ecosystem (Schmidt et al. 2011). Despite these findings, the availability of SOM-associated nutrients $(\mathrm{N}, \mathrm{P}$, and $\mathrm{S}$ ) is still considered essential for the formation of a stable soil structure to sustain crop production (Kirkby et al. 2014).

Organic input effects on crop yields are generally reported as positive in nature, although it varies with soil (Pituello et al. 2016; Hijbeek et al. 2017) and crop type (Hijbeek et al. 2017; Wei et al. 2016). For example, the recent meta-analysis by Hijbeek et al. (2017) highlighted and ordered the positive effects of organic input on crop yields as supplying nutrients to cereals first, and beyond that to some root and tuber crops second. Even though positive results are more frequently reported for cereals (maize or wheat) (Monreal et al. 1997; Wei et al. 2016; Hijbeek et al. 2017; Schjønning et al. 2018) than for root or tuber crops (potato or sugar beet) (Hijbeek et al. 2017), Schjønning et al. (2018) did report a negative, nonnutritional effect from organic input in wheat.

Therefore, this study aims to assess the effects of residue incorporation or residue incorporation with added poultry manure on crop yield. We hypothesize that aside from the general nutritional effects of crop residues, the presence of a readily-mineralisable $\mathrm{N}$ source (poultry manure) might improve soil organic matter formation, and in turn, soil properties. Consequently, this effect could improve soil conditions, and lead to increased crop performance, as measurable by yield and nitrogen use efficiency. The hypothesis was tested using a comprehensive dataset of a long-term experiment started in 1966 in the northeast of Italy in clay loam soil.

\section{Materials and methods}

The experiment

The long-term experiment used for this study is located at the experimental farm of Padova University (Veneto Region, NE Italy $45^{\circ} 21 \mathrm{~N} ; 11^{\circ} 58 \mathrm{E} ; 6 \mathrm{~m}$ a.s.l.). The sub-humid climate receives about $850 \mathrm{~mm}$ of rainfall annually, with the highest averages in June $(100 \mathrm{~mm})$ and October $(90 \mathrm{~mm})$ and the lowest averages in winter $(50-60 \mathrm{~mm})$. Temperatures rise from January (minimum average: $-1.5{ }^{\circ} \mathrm{C}$ ) to July (maximum average: $27.2{ }^{\circ} \mathrm{C}$ ). Reference evapotranspiration $\left(\mathrm{ET}_{0}\right)$ is $945 \mathrm{~mm}$ with its peaks in July $\left(5 \mathrm{~mm} \mathrm{~d}^{-1}\right) . \mathrm{ET}_{0}$ exceeds rainfall from April to September. The site has a shallow water table, ranging from about $0.5-1.5 \mathrm{~m}$ in late winter/early spring to approximately $1.0-2.0 \mathrm{~m}$ in summer.

The trial, begun in 1966, has been conducted on 64 $35 \mathrm{~m}^{2}\left(5.4 \times 6.4 \mathrm{~m}^{2}\right)$ plots in a Fluvi-Calcaric Cambisol (FAO-UNESCO 2008) with a clay loam texture. At the start of the experiment, the carbonate content was measured as $33.1 \%$, with a soil $\mathrm{pH}$ of 7.8 , bulk density of $1.44 \mathrm{~g} \mathrm{~cm}^{-3}$, organic matter content of $1.8 \%$, and an $8.3 \mathrm{C}: \mathrm{N}$ ratio in the topsoil $(0-30 \mathrm{~cm})$ (Online resources, Supplementary Table 1). The experimental treatments were derived from the factorial combination of three crop residue managements (previous crop residue incorporation (RI), previous crop residue incorporation with $1 \mathrm{t} \mathrm{ha}^{-1}$ of dried poultry manure $(\mathrm{RI}+\mathrm{PM})$, and residues removed (RR)) with five levels of nitrogen fertilisation $(0,60$, 120, 180, and $240 \mathrm{~kg} \mathrm{ha}^{-1} \mathrm{y}^{-1}$ ). The PM was applied by burying (ca. $15 \mathrm{~cm}$ ) it during shallow disk harrowing immediately after harvest. It provided $60 \mathrm{~kg}$ organic $\mathrm{N} \mathrm{ha}^{-1}$. Until 1981, mineral $\mathrm{N}$ was 
applied as ammonium-nitrate, after which urea was used.

Mineral $\mathrm{N}$ was supplied in two top-dressing applications. In spring and summer crops, $\mathrm{N}$ distribution was followed by an inter-row cultivation (ca. $7 \mathrm{~cm}$ ). Residue incorporation occurred during soil tillage in a 40/45-cm autumn ploughing and subsequent seedbed preparation (e.g., 10-cm disk harrowing). All treatments received the same amounts of $\mathrm{P}\left(65.5 \mathrm{~kg} \mathrm{ha}^{-1}\right.$ $\left.\mathrm{y}^{-1}\right)$ and $\mathrm{K}\left(124.5 \mathrm{~kg} \mathrm{ha}^{-1} \mathrm{y}^{-1}\right)$ at sowing by mineral fertilisers. The trial was designed as a split-plot of four blocks with residue management as the main plot; fertilisation levels and one unfertilised control plot were randomised inside the main plot. Prior to 1984 , the trial was conducted with maize (Zea mays L.) in monoculture. Thereafter a variable rotation scheme was used based mainly on maize, sugar beet (Beta vulgaris L.), winter wheat (Triticum aestivum L.), potato (Solanum tuberosum L.), soybean (Glycine max (L.) Merr.), and tomato (Solanum lycopersicum L.) (Online resource, Supplementary Fig. 1). For a single year sorghum (Sorghum vulgare Pers.) and sunflower (Helianthus annuus L.) were also grown. The potato crop failed in 2009 , so the data were removed for the purposes of this study.

At the end of each growing season (1966-2017), the fresh yields and residue biomasses of each plot were weighted and were dried in a $65^{\circ} \mathrm{C}$ oven until constant weight, to determine the dry weight. Average $\mathrm{N}$ content yield and residue biomass values used for further calculations are given in Online resource, Supplementary Table 2.

\section{Calculation and statistical analysis}

The long-term effect of different residue managements was subjected to a dual-step statistical analysis (Online resources, Supplementary Fig. 2). At first, a mixed model was applied to test the effect of residue management, applied $\mathrm{N}$, and their interaction on crop yield. All of these effects were treated as fixed, while the block and year were treated as random effects. In cases of residue management significance, a post hoc pair-wise comparison of least-squares means was performed using Tukey's test to adjust for multiple comparisons. Three effects can reasonably result from Tukey's test: (1) effect of residue incorporation alone (RI and RI + PM > RR), (2) effect of added poultry manure to RI (RI + PM > RI and RR), or (3) effects of both RI and added poultry manure to RI (RI + $\mathrm{PM}>\mathrm{RI}>\mathrm{RR})$. Therefore, two hyperbolic models (complex model (CM) and simplified model (SM)) were fitted to the yield trendline and then compared with a partial $F$-test, considering as significant $p \leq 0.05$. The hyperbolic models described the relationships between applied mineral $\mathrm{N}\left(N_{\text {app }}\right)$, namely 0 , $60,120,180$ and $240 \mathrm{~kg} \mathrm{ha}^{-1}$, and yield according to the following equation, derived from Vos (1997):

Yield $=Y_{0}+\frac{a \times N_{a p p}}{1+\left(\frac{a \times N_{a p p}}{b}\right)}$

where $Y_{0}$ is the yield without $\mathrm{N}$ distribution (control plot), $a$ is the initial slope, and $b$ is the difference between the asymptotic maximum yield $\left(Y_{M}\right)$ and $Y_{0}$. To directly express the maximum yield as a function parameter, Eq. (1) was rewritten as:

Yield $=Y_{M}-b+\frac{a \times N_{a p p}}{1+\left(\frac{a \times N_{a p p}}{b}\right)}$.

In SM, $Y_{M}$ was unaffected by residue management, and only $a$ and $b$ parameters varied. In CM, all parameters $\left(Y_{M}, a\right.$ and $\left.b\right)$ changed among the treatments according to Tukey's test. Whenever the difference between CM and SM was significant, the organic input was considered to have a nutritional plus structural or biological effect ("non-Ntr effect"); otherwise, for $p$ values $>0.05$, the SM was considered as adequate to describe the treatment effects on yield, i.e., organic input effect was considered as nutritional only ("Ntr effect"). The expectation in case categorized as producing a Ntr effect is that organic inputs undergo rapid mineralisation, which allows crop roots to intercept nutrients with no effect on potential crop yield. Thereafter, the effect of organic input should produce an increased $\mathrm{N}$ availability, graphically depicted by an increasing $Y_{0}$, decreasing $a$ and $b$, and non-variable $Y_{M}$. In other words, the curve approaches the asymptote at lower mineral $\mathrm{N}$ application rate (Fig. 1a). On the other hand, if organic input also evokes other soil dimension amelioration, as in the case of a non-Ntr effect, an improvement of SOC-related characteristics, such as soil structure, porosity, and water retention would be expected. In this case, the asymptote $\left(Y_{M}\right)$ would be expected to increase, but the behaviour of the other parameters is not directly predictable (Fig. 1b). 
(a) Ntr effect

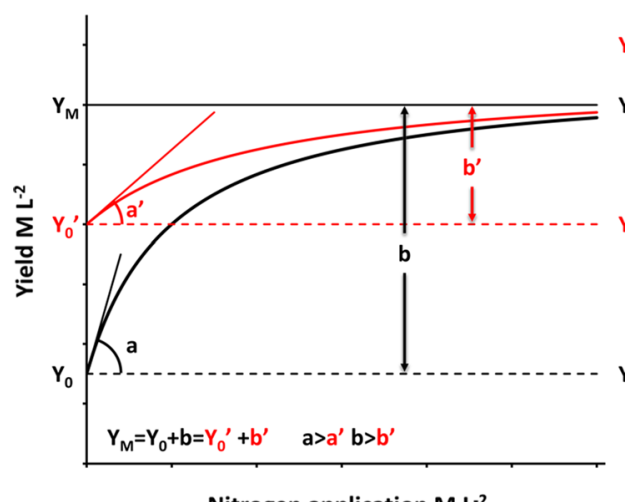

Nitrogen application $\mathrm{M} \mathrm{L}^{-2}$

Fig. 1 Representation of hyperbolic model used to describe the relationship between crop yield and applied N. Parameter $Y_{0}$ is the yield without any $\mathrm{N}$ supply, and $a$ and $b$ are the initial slope and difference between $Y_{M}$ and $Y_{0}$, respectively. a In case of nutritional (Ntr) effect, the expectation is that $Y_{0}{ }^{\prime}$ will be greater

To estimate the amounts of $\mathrm{N}$ recovered from mineral fertilisation $\left(N_{\text {rec_min }}\right), \mathrm{RI}\left(N_{\text {rec_RI }}\right)$ and $\mathrm{RI}+$ PM $\left(N_{\text {rec_RI }+P M}\right)$, observed $\mathrm{N}$ recoveries were fitted with the following equations:

$$
\begin{aligned}
& N_{\text {rec_min }}=N_{0}+\frac{\left(N_{\min } \times k_{\min }\right) \times c}{1+\left(\frac{\left(N_{\min } \times k_{\min }\right) \times c}{d}\right)} \\
& N_{\text {rec_RI }}=N_{0}+\frac{\left(N_{\min } \times k_{\min }+N_{R I} \times k_{R I}\right) \times c}{1+\left(\frac{\left(N_{\min } \times k_{\min }+N_{R I} \times k_{R I}\right) \times c}{d}\right)} \\
& N_{\text {rec_RI+PM }}=N_{0} \\
&+\frac{\left(N_{\min } \times k_{\min }+N_{R I+P M} \times k_{R I+P M}\right) \times c}{1+\left(\frac{\left(N_{\min } \times k_{\min }+N_{R I+P M} \times k_{R I+P M}\right) \times c}{d}\right)}
\end{aligned}
$$

where $N_{0}$ is the naturally-available soil $\mathrm{N}$ for a specific crop, calculated as the average $\mathrm{N}$ recovered by crop in RR treatment with no mineral nitrogen application. The $N_{\text {min }}, N_{R I}$, and $N_{R I+P M}$ are the amounts of $\mathrm{N}$ from mineral fertiliser (ranging from 0 to $240 \mathrm{~kg} \mathrm{ha}^{-1}$ ), residues, and residue with poultry litter, respectively. The residue-derived $\mathrm{N}$ fraction was calculated from the residue of the previous year and ranged from 0 (in RR treatment) to $203.2 \mathrm{~kg} \mathrm{ha}^{-1}$ while the poultry manure-derived $\mathrm{N}$ fraction was $0 \mathrm{~kg} \mathrm{ha}^{-1}$ in $\mathrm{RI}$ and $\mathrm{RR}$, and $60 \mathrm{~kg} \mathrm{ha}^{-1}$ in RI + PM. The $c, d, k_{\text {min }}, k_{R I}$, and $k_{R I+P M}$ are regression parameters, with the three
(b)non-Ntr effect

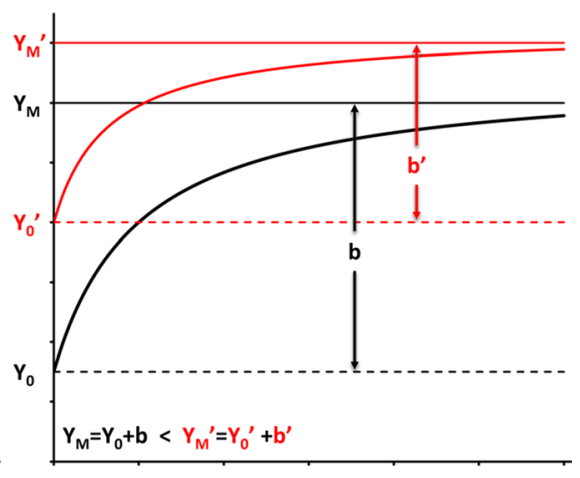

Nitrogen application $\mathrm{M} \mathrm{L}^{-2}$

than $Y_{0}, a^{\prime}$ and $b^{\prime}$ will be lower than $a$ and $b$, and $Y_{M}$ will not change. b In cases of non-nutritional (non-Ntr) effect, $Y_{M}{ }^{\prime}$ is expected to increase, while the behaviour of the other parameters is not directly predictable

$\mathrm{k}$-values indicating nitrogen availability for mineral fertiliser, residue, and residues with poultry litter, respectively.

The Nitrogen use efficiency (NUE) of mineral fertiliser $\left(N U E_{\text {min }}\right)$, residue $\left(N U E_{R I}\right)$ and residue with added poultry manure $\left(N U E_{R I+P M}\right)$ was then be obtained dividing the $\mathrm{N}$ recovered from a specific source by the $\mathrm{N}$ distributed:

$$
\begin{aligned}
N U E_{\text {min }}= & \left(N_{\text {rec_min }}-N_{0}\right) \\
& \times \frac{k_{\text {min }}}{N_{\text {min }} \times k_{\min }+N_{R I} \times k_{R I}+N_{R I+P M} \times k_{R I+P M}} \\
N U E_{R I}= & \left(N_{\text {rec_RI }}-N_{0}\right) \frac{k_{R I}}{N_{\text {min }} \times k_{\min }+N_{R I} \times k_{R I}}
\end{aligned}
$$

and

$$
\begin{aligned}
N U E_{R I+P M}= & \left(N_{\text {rec } \_R I+P M}-N_{0}\right) \\
& \times \frac{k_{R I+P M}}{N_{\text {min }} \times k_{\min }+N_{R I+P M} \times k_{R I+P M}}
\end{aligned}
$$

The mixed models were performed with SAS (SAS Institute Inc. Cary, NC, USA) version 5.1 and hyperbolic model fitting relied on the Microsoft Excel Solver add-in tool. 


\section{Results}

Crop yield

The trend of maize biomass production was inconsistent during the shift from monoculture (until 1984) to variable rotation adopted in 1985 (Online resource, Supplementary Fig. 3). Before 1985, average maize yield was $6.15 \mathrm{t} \mathrm{ha}^{-1}$, with a minimum of $3.65 \mathrm{t} \mathrm{ha}^{-1}$ (1966) and a maximum of $8.20 \mathrm{t} \mathrm{ha}^{-1}$ (1984). Once crop rotation was adopted, average maize yield increased by about $3 \mathrm{tha}^{-1}$ and ranged from $5.40 \mathrm{t} \mathrm{ha}^{-1}$ (2013) to $16.68 \mathrm{t} \mathrm{ha}^{-1}$ (2017). In winter wheat, the average yield was $5.17 \mathrm{t} \mathrm{ha}^{-1}$ and fell within a far smaller range of $3.50 \mathrm{t} \mathrm{ha}^{-1}$ in 2007 to ca. $6.60 \mathrm{t} \mathrm{ha}^{-1}$ in 2011 . The adverse pedo-climatic conditions in 2012 and 2016 affected sugar beet yields, such that they dropped from an average of 13.66 between 1989 and 2008 to $9.01 \mathrm{t} \mathrm{ha}^{-1}$ during the last 2 years of cultivation. Potato and tomato were grown for just three and 2 years, respectively. The 2009 potato production was unusually low $(-81 \%$, on average), so its data were excluded from the statistical analyses. Tomato, on the other hand exhibited stable yields (5.29 $\mathrm{t} \mathrm{ha}^{-1}$, on average); its data were included and analysed.

The mixed model results always demonstrated a significant effect of $N_{a p p}$ on yield. On the contrary, residue management and its interaction with $N_{a p p}$ effects depended on crop type. Specifically, residue incorporation had a positive effect on maize yield, as indicated by higher averages for RI + PM and RI (7.65 $\mathrm{t} \mathrm{ha}^{-1}$ ) compared to the average for $\mathrm{RR}$ $\left(6.84 \mathrm{t} \mathrm{ha}^{-1}\right)$ (Online resource, Supplementary Tables 3 and 4). The $N_{\text {app }}$ raised the average maize yield from $5.15 \mathrm{t} \mathrm{ha}^{-1}$ (no $\mathrm{N}$ supply) to $8.00 \mathrm{t} \mathrm{ha}^{-1}$ $\left(120 \mathrm{~kg} \quad N_{a p p} \mathrm{ha}^{-1}\right)$ to $8.37 \mathrm{t} \mathrm{ha}^{-1} \quad\left(N_{a p p-}\right.$ $\geq 180 \mathrm{~kg} \mathrm{ha}^{-1}$ ). Winter wheat was affected by the interaction of residue management $\times N_{a p p}$ $(p=0.011)$. The effect of adding poultry manure to RI was significant (4.29 vs $3.35 \mathrm{t} \mathrm{ha}^{-1}$ ) when $N_{\text {app- }}$ $\leq 60 \mathrm{~kg} \mathrm{ha}^{-1}$, but no differences were observed at higher $N_{a p p}$ doses. Similarly, potato yields were affected by residue management $\times N_{a p p}$ interaction $(p<0.01)$, such that $\mathrm{RI}+\mathrm{PM}$ resulted with the highest yield (5.49 vs $4.01 \mathrm{t} \mathrm{ha}^{-1}$ ) at $N_{a p p}$ equal to $0 \mathrm{~kg} \mathrm{ha}^{-1} \mathrm{y}^{-1}$. The combination of added poultry manure and residue incorporation significantly increased yield only when $N_{a p p} \leq 60 \mathrm{~kg} \mathrm{ha}^{-1}$. At higher levels of $N_{a p p}$, no residue management effects were observed. Across all residue management approaches, $N_{a p p}$ increased yields through additions of $120 \mathrm{~kg} \mathrm{~N} \mathrm{ha}^{-1}$. Sugar beet was the only crop in which poultry manure and crop residue incorporation produced different results. In this crop, yields for $\mathrm{RI}+\mathrm{PM}\left(13.43 \mathrm{t} \mathrm{ha}^{-1}\right)>\mathrm{RI}\left(12.55 \mathrm{t} \mathrm{ha}^{-1}\right)>\mathrm{RR}$ $\left(10.84 \mathrm{t} \mathrm{ha}^{-1}\right)$, irrespective of $N_{\text {app }}$. Last, tomato crop was unaffected by residue management $(p>0.05)$, as evidenced by progressively increasing yields from 3.06 (no $\mathrm{N}$ supply) to $6.58 \mathrm{t} \mathrm{ha}^{-1}\left(N_{a p p}\right.$ equal to $\left.180 \mathrm{~kg} \mathrm{ha}^{-1}\right)$.

Yield response to $\mathrm{N}$ application with different crop residue managements

A CM was fitted and compared to a SM for four (maize, potato, sugar beet, and wheat) of the five crops affected by residue management (Table 1). In contrast to the other crops, tomato required that a unique series of parameters $\left(a, b, Y_{M}\right)$ be fitted to model the rise of its yield (initial slope of 0.040 and $Y_{\max }$ of $9.06 \mathrm{t} \mathrm{ha}^{-1}$ ) in response to $\mathrm{N}$ application (Fig. 2). As mentioned earlier, potato data from a mineral $\mathrm{N}$ input above $180 \mathrm{~kg} \mathrm{~N} \mathrm{ha}^{-1}$ were excluded from the non-linear interpolation for the crop, as the hyperbolic model did not account for the decline in yield at the highest level of $N_{\text {app }}$. The poultry manure added to residues had a $\mathrm{Ntr}$ effect on potato, as indicated by the lack of statistical difference $(p=0.202)$ between CM and SM. The RI + PM treatment resulted in a $37 \%$ higher $Y_{0}$, four orders of magnitude lower $a$, and a halved $b$, compared to RI and RR. Maize yields exhibited different patterns "with" (RI and RI + PM) and "without" (RR) residue incorporation. PM had no effect on crop performance. Comparison of the maize $\mathrm{CM}$ and SM failed to show a statistical difference $(p=0.888)$, which suggests a sole Ntr effect from residue incorporation (Table 1). The initial slope ( $a$ parameter) rose about $6 \%$, and $Y_{0}$ (i.e., yield with no additional $\mathrm{N}$ supply) increased from 4.42 to $5.52 \mathrm{t} \mathrm{ha}^{-1}$ with residue incorporation. Sugar beet yield was affected by both residue incorporation $(p=0.037)$, a non-Ntr effect, and poultry manure ( $p=0.297)$, a Ntr effect (Fig. 2 and Table 1).

As noted previously, sugar beet growth was affected by adverse climatic condition in 2012 and 2016. However, removing these 2 years from the dataset changed neither the fitting results, nor the 
Table 1 Comparisons of complex (CM) and simplified (SM) models of the relationship between crop yield and N supply

\begin{tabular}{lllll}
\hline Crop & Treatments involved & F value & $p$ value & Effect \\
\hline Maize & RI and RI + PM versus RR & 0.0212 & 0.8875 & Ntr effect \\
Potato & RI + PM versus RI and RR & 2.0522 & 0.2020 & Ntr effect \\
Sugar beet & RI versus RR & 9.5698 & 0.0365 & non-Ntr effect \\
& RI versus RI + PM & 1.4334 & 0.2973 & Ntr effect \\
Wheat & RI + PM versus RI and RR & 2.5706 & 0.1433 & Ntr effect \\
\hline
\end{tabular}

In cases of significant differences, the effect on yield is considered a non-Ntr effect, else only a Ntr effect. Model results are reported only for crops affected by residue management in the mixed effect model

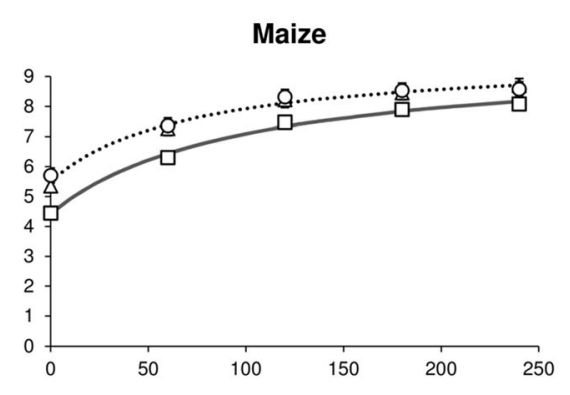

Sugar beet

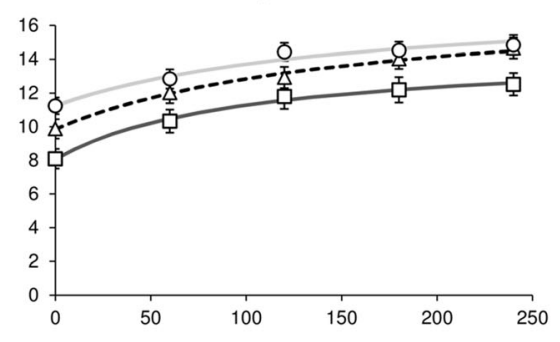

Winter wheat

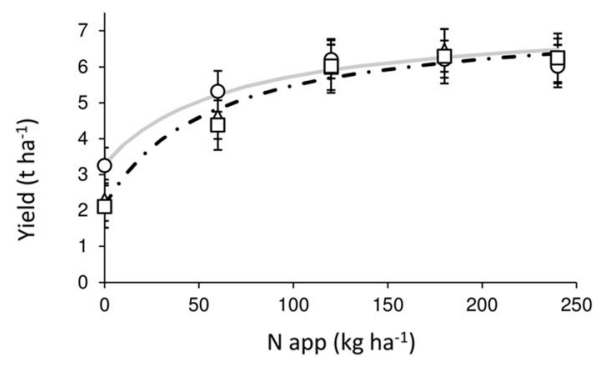

Fig. 2 Crop yield response to applied $\mathrm{N}\left(\mathrm{N}_{\text {app }}\right)$ for the studied crops. Symbols represent observed results; curves represent the model results. If residue management did not affect crop yield,

conclusions, which made it suitable to consider the full set of years for subsequent analyses. For this crop, $Y_{M}$ was $14.49 \mathrm{t} \mathrm{ha}^{-1}$ in RR and $18.86 \mathrm{t} \mathrm{ha}^{-1}$ in RI, with

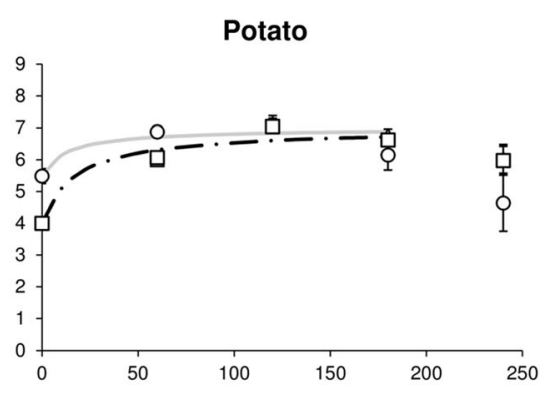

Tomato

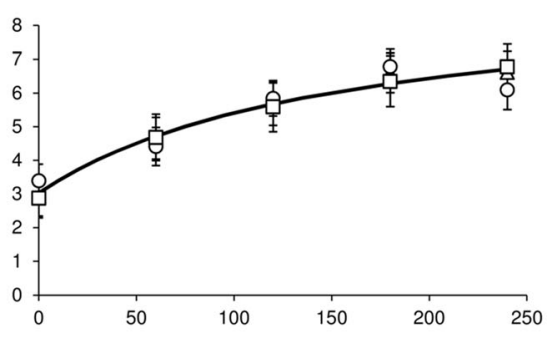

Legend

Average data

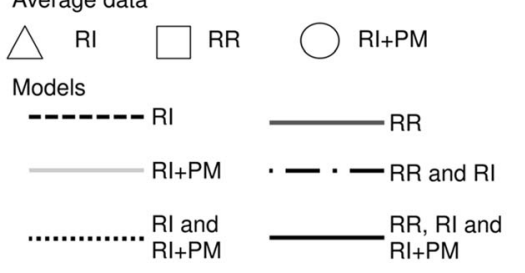

only one model was fitted to the data. In instances of the contrary, more than one model was fitted according to Tukey's test and a partial $F$-test was performed on the hyperbolic models

initial slopes of 0.065 and 0.042 , respectively. Yield rose more than $1.7 \mathrm{tha}^{-1}(+22 \%)$ when residues were incorporated with no additional $\mathrm{N}$ supply $\left(Y_{0}\right)$ 
(Fig. 2). On the other hand, added PM did not raise maximum yield, but increased $a$ by about $16 \%$ and reached a $Y_{0}$ of $11.20 \mathrm{t} \mathrm{ha}^{-1}$. Similarly, a Ntr effect was observed in winter wheat when PM was incorporated with crop residues $(p>0.05)$ (Table 1). Here, the initial slope fell almost two-fold, from 0.093 to 0.062 , while yield increased by $1.14 \mathrm{t} \mathrm{ha}^{-1}(+53 \%)$ with no $\mathrm{N}$ supply. Poultry manure most affected yield at lower fertilisation doses, and in particular, at $N_{\text {app }}<120 \mathrm{~kg} \mathrm{ha}^{-1}$ (Fig. 2).

$\mathrm{N}$ recovery and nitrogen use efficiency (NUE)

Fitting the model to the observed data resulted in a natural $\mathrm{N}$ availability $\left(N_{0}\right)$ that varied from $80.9 \mathrm{~kg} \mathrm{~N} \mathrm{ha}^{-1}$ (maize) to $40.6 \mathrm{~kg} \mathrm{~N} \mathrm{ha}^{-1}$ (winter wheat), and for which the asymptotic maximum $\mathrm{N}$ uptakes ( $d$ parameter) ranged from 65.0 (potato) to $281.0 \mathrm{~kg} \mathrm{~N} \mathrm{ha}^{-1}$ (winter wheat) (Table 2). Except for sugar beet, the constants related to nitrogen availability of $\mathrm{N}$ inputs $\left(k_{\min }, k_{\text {res }}\right.$, and $\left.k_{R I+P M}\right)$ were always higher for the mineral inputs, ranging from 0.30 in maize to 3.95 in winter wheat. The value of $k_{\text {res }}$ was approximately double that of $k_{R I+P M}$ in maize $(0.26 \mathrm{vs}$ 0.12 ) and sugar beet (2.11 vs 1.16 ), while RI + PM exhibited greater availability in potato $(0.42$ vs 0.02$)$, tomato (0.16 vs 0.14$)$, and winter wheat ( 0.80 vs 0.54$)$. In addition, it was noted that the lowest $k_{\text {res }}$ values were associated with solanaceous crops (potato and tomato) (Table 2).

The models estimated nitrogen use efficiency $(N U E)$ for each $\mathrm{N}$ type: mineral fertiliser $\left(N U E_{\text {min }}\right)$, crop residue $\left(N U E_{R I}\right)$, and crop residue + poultry manure ( $\left.N U E_{R I+P M}\right)$ (Fig. 3). The $N U E_{\text {min }}$ was always greater than all other sources ( 0.54 vs 0.19 , on average) except in sugar beet, for which the rank order was $N U E_{\text {res }}(0.62)>N U E_{R I+P M}$ $(0.53)>N U E_{\min }(0.47)$. Residue incorporation was linked to higher NUEs from RI + PM in maize and sugar beet, whereas RI + PM improved the NUEs from RI treatment in potato and winter wheat $(0.29 \mathrm{vs}$ 0.07 on average). The $N U E_{R I}$ of potato was very low (0.008).

\section{Discussion}

Crop yield and organic input

Long-term soil management with different organic inputs (e.g., crop residues and poultry manure) was shown to increase crop yields beyond the background variation caused by crop type and seasonal climate conditions. Despite the widely-held view that organic inputs enhance crop yields (e.g., Monreal et al. 1997; Pituello et al. 2016; Wei et al. 2016; Hijbeek et al. 2017; Schjønning et al. 2018), the nature of their mutually beneficial relationship is still a matter for debate. Indeed, it is difficult to assert that yields rise due to improved soil conditions or vice versa. As speculated by Hijbeek et al. (2017), the two possibilities might co-exist. This suggests that greater organic input may promote higher yields, which puts additional $\mathrm{C}$ into the soil and improves soil properties. In turn, yields are boosted, SOM is increased, and SOMrelated properties are enhanced.

In this study, the most important effect of organic inputs on yields stemmed from crop type: incorporation of crop residues improved maize and sugar beet yields by 12 and $16 \%$, respectively, while poultry

Table 2 Parameters of the model describing $\mathrm{N}$ recovery for each crop

\begin{tabular}{lllllllrrr}
\hline Crop & $N_{0}$ & $k_{\min }$ & $K_{\text {res }}$ & $k_{R I+P M}$ & $c$ & $D$ & $S S_{\text {residual }}$ & $S S_{\text {total }}$ & $N$ \\
\hline Maize & 80.9 & 0.30 & 0.26 & 0.12 & 2.4 & 151.33 & 69.8 & $10,263.3$ \\
Potato & 71.7 & 1.46 & 0.02 & 0.42 & 1.3 & 65.0 & 342.9 & 4722.5 \\
Sugar beet & 67.6 & 1.63 & 2.11 & 1.16 & 0.34 & 624.64 & 116.8 & $25,697.1$ & 15 \\
Tomato & 67.1 & 1.76 & 0.14 & 0.16 & 0.57 & 136.10 & 435.5 & $13,783.0$ \\
Winter wheat & 40.6 & 3.95 & 0.54 & 0.80 & 0.37 & 281.0 & 241.4 & $42,782.7$ \\
\hline
\end{tabular}

$N_{0}$ : amount of $\mathrm{N}$ recovered from natural soil availability; $k_{\text {min }}$ : nitrogen availability from mineral fertiliser; $k_{\text {res }}$ : nitrogen availability from residue incorporation; $k_{R I+P M}$ : nitrogen availability from poultry manure; $c$ and $d$ : regression parameters; $S S_{\text {residual }}$ :residual sum of square; $S S_{\text {total }}$ : total sum of square; n: number of observations 
(a) Maize

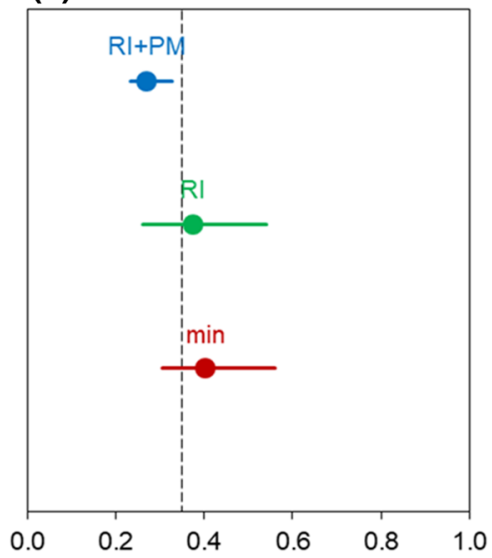

(d) Tomato

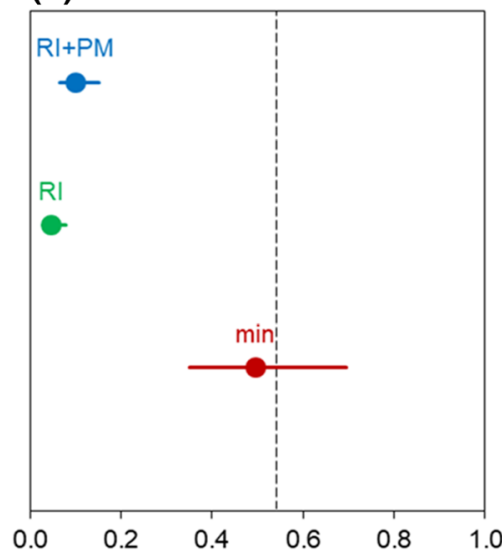

(b) Potato

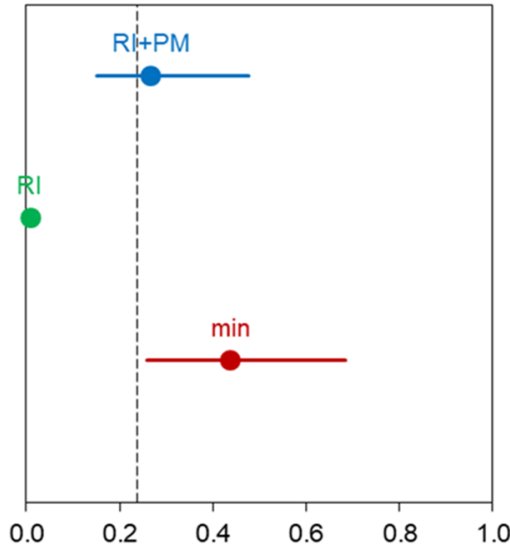

(c) Sugar beet

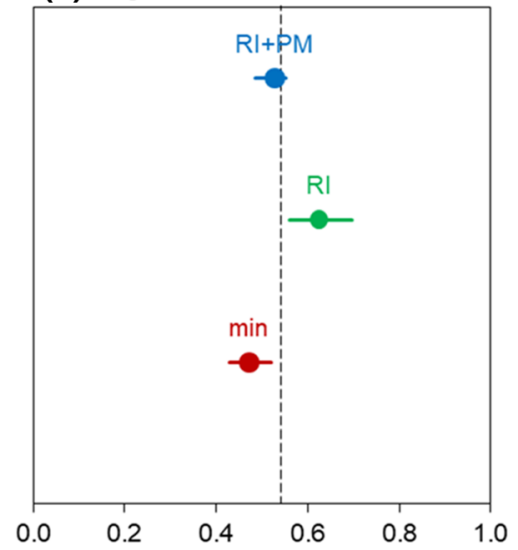

(e) Winter wheat

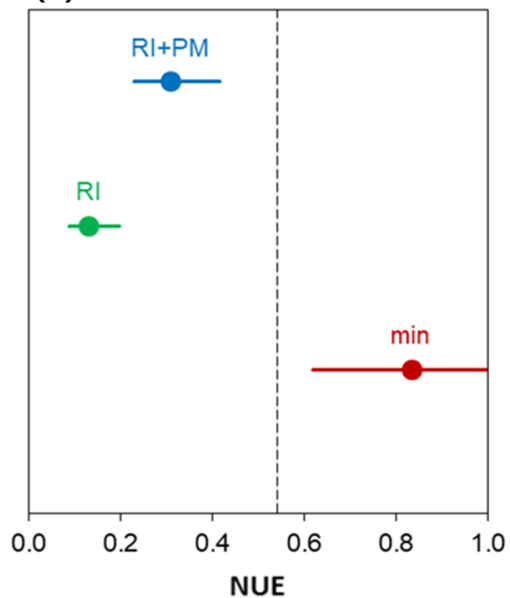

Fig. 3 Nitrogen use efficiency (NUE) of mineral ( $\mathrm{min}$ ), crop residue incorporation (RI), and crop residue + poultry manure $(\mathrm{RI}+\mathrm{PM})$. Vertical dashed lines represent NUE averages, regardless of residue management

manure added to RI increased winter wheat by $7 \%$, sugar beet by $7 \%$, and potato yields by $1 \%$. The literature often states that maize yield is improved by adding C, as found by both Wei et al. (2016) and Hijbeek et al. (2017) (ca. 4\% rise in maize grain production). By contrast, Chinese and European longterm experiments involving wheat cropping have reported varied results: positive (Monreal et al. 1997; Wei et al. 2016), neutral (Hijbeek et al. 2017), and negative (Schjønning et al. 2018). Optimal results were observed in sugar beet, a finding that confirmed that the crop might attain peak production under loamy soils with organic inputs (Fageria 2012; Pituello et al. 2016).
In Northern Italy, water availability during the winter wheat growing season is typically ample for the crop, but spring-summer crops frequently endure periods of little rainfall and high temperatures. Nevertheless, the positive effects on soil structure from residues likely counter these climate hazards in a more pronounced way for crops such as maize and sugar beet than they do for wheat. Furthermore, the loamy soil of the experimental site warms more slowly at the beginning of spring, thus limiting crop residue mineralisation in the early months of the year. While this can restrict the interception of mineralised $\mathrm{N}$ in a wheat crop, it can increase the synchronization of absorption peaks with residue mineralisation in spring-summer crops. Organic input derived from 
agronomic sources (residues and animal waste) can promote not only higher yields, but also soil buffering in years with less favourable conditions, thereby reducing yield variability (Pan et al. 2009). Indeed, in severe dry or wet conditions, crops may potentially benefit from organic inputs as SOM (Díaz-Zorita et al. 1999) expands the water-holding capacity of soil and prevents its compaction (Soane 1990).

\section{Organic input effect, Ntr or non-Ntr effect}

Four of the five crops responded to additional organic input. Each was investigated through model comparison for the presence of a Ntr or non-Ntr effect. Organic inputs had a Ntr effect on maize, potato, and winter wheat, albeit maize benefited from residue incorporation alone while the other two did so from the addition of poultry manure to residue. In sugar beet, an impact from either residue (non-Ntr effect) or residue + poultry manure (Ntr effect) was confirmed by model comparison.

At the start of the experiment, the application of poultry manure with crop residues was intended to reduce the $\mathrm{C}: \mathrm{N}$ ratio of the organic materials incorporated to promote residue decomposition, and in turn, SOM formation. However, results indicated that this effect, if present at all, was negligible. Instead, the poultry manure added to crop residues acted as an additional $\mathrm{N}$ source, with an efficiency highly dependent on crop characteristics.

The benefits to spring-sown crop yields have previously been linked to the shorter time spans that such crops need to develop appropriate root systems for nutrient uptake (Johnston et al. 2009). In this study, autumn-sown winter wheat production also improved by the addition of poultry manure, an effect that might be attributed to manure-derived available nutrients. Furthermore, the fact that poultry manure was applied immediately after harvest allows for the speculation that its nutrients might be more available to autumnsown, as opposed to spring-sown crops. Studies have also suggested that the potential exists for SOM benefits beyond nutrient supplies, especially in root or tuber crops (de Haan 1977). The work of de Haan (1977) has, indeed, put forth the notion of such a positive non-Ntr effect from farmyard manure in both potato and sugar beet, but not in cereals. Similar findings have also been suggested quite recently by Hijbeek et al. (2017), who speculated that such crops depend more on improved soil structure than do cereals for successful cultivation and harvesting. This theory aligns with our results in sugar beet, which benefitted from the non-Ntr effect of RI. On the other hand, PM added to residues only increased $\mathrm{N}$ availability; it did not affect potential yield. This result corroborates not only the high mineralisation rate of poultry manure, but also its minimal effect on SOC accumulation (Maillard and Angers 2014).

Another finding to highlight is the effect of $\mathrm{N}$ fertilisation on crop performance. Nevens and Reheul (2002) differentiated Ntr from non-Ntr effects. They also stressed the importance of determining non-Ntr effects under non-N limiting circumstances, namely at high mineral $\mathrm{N}$ fertiliser rates. In this study, this condition was not always met because the experimental design resulted from the factorial combinations of three residue managements and five $\mathrm{N}$ levels $(0,60$, 120,180 , and $240 \mathrm{~kg} \mathrm{~N} \mathrm{ha}^{-1}$ ), in which the lower $\mathrm{N}$ levels were reasonably limiting for most of the studied crops.

\section{Nitrogen recovery and NUE}

Discussion of $\mathrm{N}$ recovery and NUE results as they relate to other research is best served by first highlighting some methodological details that may have had an effect. Indeed, the model used for $\mathrm{N}$ recovery estimation relies on some assumptions. First, natural $\mathrm{N}$ availability ( $N_{0}$ parameter) is unique in all treatments and is strongly related to $\mathrm{N}$ adsorption in plots receiving no nitrogen. After 50 years of different fertilisation, it is reasonable that $N_{0}$ should vary in highly-fertilised plots, but the design of experiment did not permit consideration of this type of variation. If $N_{0}$ is a constant, then fertilised plot NUEs would be overestimated, and we speculate that the effect might be more evident at lower fertilisation levels. Second, as the model does not explicitly consider the interaction between mineral and organic $\mathrm{N}$ forms, results should first be considered as estimates of real efficiencies.

Mineral NUE values were mostly higher compared to those of residues and residues + poultry manure. The exception to this was sugar beet, which had a $36 \%$ greater $N U E_{R I}$ that $N U E_{\text {min }}$. In similar climatic conditions but different soils, Pituello et al. (2016) postulated that the residue incorporation efficiency for a similar crop appeared more pronounced, especially 
in soils of low fertility. The maize crop residue $N U E$ was similar to that of mineral inputs, which substantiated the positive effect gained from incorporating organic materials in these crops. Our experiment was conducted in clay loam soil with an initial SOM of about $1.8 \mathrm{~g} 100^{-1} \mathrm{~g}$ that remained stable across the years (Lugato et al. 2006; Poeplau et al. 2017). For all of these reasons, we recommended that this practice be utilised in such soils to maintain their fertility (Pituello et al. 2016). The increase of NUE due to the addition of poultry manure to residues is remarkable in winter wheat. The temporal proximity when wheat is sown and poultry manure is applied, coupled with the lower temperature during its growing season, may explain the higher efficiency of manure on winter wheat. However, it seems that for wheat, organic inputs result in far lower NUEs than does mineral fertiliser, which by its application in two top-dressings aligns better with crop absorption dynamics.

\section{Conclusions}

According to the results presented in this study, our starting hypothesis that adding poultry manure to crop residues has a positive effect beyond the general nutritional aspect is rejected. In fact, no clear non-Ntr effect was apparent. Moreover, the nutritional effect of poultry manure was enhanced when it was applied close to sowing which increased $\mathrm{N}$ uptake. In most crops, the effect of residues is mainly related to their nutrient content, which suggests that an almost complete decomposition of crop residues occurs within 1 year. The potential use of this practice for $\mathrm{C}$ sequestration might then be low. Nevertheless, by combining organics and mineral fertilisers, the need for future chemical inputs may be reduced, which would result in a positive impact on global fossil fuel demand. Future studies related to this topic should focus on the effects of different residue types on subsequent crops, on the SOC dynamics in stabilized cropping systems, and on the potential for interaction in climate change scenarios.

Acknowledgements The research leading to these results has received funding from the European Union HORIZON2020 Programme for Research, Technological Development, and Demonstration under Grant Agreement No. 677407 (SOILCARE Project), and from the Italian Ministry of Education, University and Research (MIUR) through several
PRIN Projects (Grants Nos. 2002071492, 2005071990, 2007J5Z9LK, and 2010FRE7J4).

Open Access This article is licensed under a Creative Commons Attribution 4.0 International License, which permits use, sharing, adaptation, distribution and reproduction in any medium or format, as long as you give appropriate credit to the original author(s) and the source, provide a link to the Creative Commons licence, and indicate if changes were made. The images or other third party material in this article are included in the article's Creative Commons licence, unless indicated otherwise in a credit line to the material. If material is not included in the article's Creative Commons licence and your intended use is not permitted by statutory regulation or exceeds the permitted use, you will need to obtain permission directly from the copyright holder. To view a copy of this licence, visit http://creativecommons.org/licenses/by/4.0/.

\section{References}

Berti A, Morari F, Dal Ferro N, Simonetti G, Polese R (2016) Organic input quality is more important than its quantity: $\mathrm{C}$ turnover coefficients in different cropping systems. Eur J Agron 77:138-145. https://doi.org/10.1016/j.eja.2016.03. 005

de Haan S (1977) Humus, its formation, its relation with the mineral part of the soil, and its significance for soil productivity. In: International Atomic Energy Agency (ed) Soil organic matter studies. IAEA, Vienna, pp 21-30

Díaz-Zorita M, Buschiazzo DE, Peinemann N (1999) Soil organic matter and wheat productivity in the semiarid argentine pampas. Agron J 91:276-279. https://doi.org/10. 2134/agronj1999.00021962009100020016x

Fageria NK (ed) (2012) Management strategies for maximizing root systems. In: The role of plant roots in crop production. CRC Press, Boca Raton, pp 369-442

FAO-UNESCO (2008) Soil map of the world: revised legend. Food and Agriculture Organization of the United Nations, Rome

Hijbeek R, van Ittersum MK, ten Berge HFM et al (2017) Do organic inputs matter: a meta-analysis of additional yield effects for arable crops in Europe. Plant Soil 411:293-303. https://doi.org/10.1007/s11104-016-3031-x

Himes FL (2018) Nitrogen, sulfur, and phosphorus and the sequestering of carbon. In: Lal R, Kimble JM, Follett RF, Stewart BA (eds) Soil processes and the carbon cycle. CRC Press, Boca Raton, pp 315-319

Johnston AE, Poulton PR, Coleman K (2009) Soil organic matter: its importance in sustainable agriculture and carbon dioxide fluxes. Adv Agron 101:1-57. https://doi.org/10. 1016/S0065-2113(08)00801-8

Kätterer T, Bolinder MA, Andrén O et al (2011) Roots contribute more to refractory soil organic matter than aboveground crop residues, as revealed by a long-term field experiment. Agric Ecosyst Environ 141:184-192. https:// doi.org/10.1016/j.agee.2011.02.029

Kirkby CA, Richardson AE, Wade LJ, Passioura JB, Batten GD, Blanchard C, Kirkegaard JA (2014) Nutrient availability 
limits carbon sequestration in arable soils. Soil Biol Biochem 68:402-409. https://doi.org/10.1016/j.soilbio.2013. 09.032

Kleber M, Johnson MG (2010) Advances in understanding the molecular structure of soil organic matter: implications for interactions in the environment. Adv Agron 106:77-142. https://doi.org/10.1016/S0065-2113(10)06003-7

Lehmann J, Solomon D, Kinyangi J, Dathe L, Wirick S, Jacobsen C (2008) Spatial complexity of soil organic matter forms at nanometre scales. Nat Geosci 1:238-242. https://doi.org/10.1038/ngeo155

Lugato E, Berti A, Giardini L (2006) Soil organic carbon (SOC) dynamics with and without residue incorporation in relation to different nitrogen fertilisation rates. Geoderma 135:315-321. https://doi.org/10.1016/j.geoderma.2006.01. 012

Maillard É, Angers DA (2014) Animal manure application and soil organic carbon stocks: a meta-analysis. Glob Chang Biol 20:666-679. https://doi.org/10.1111/gcb.12438

Monreal CM, Zentner RP, Robertson JA (1997) An analysis of soil organic matter dynamics in relation to management, erosion and yield of wheat in long-term crop rotation plots. Can J Soil Sci 77:553-563. https://doi.org/10.4141/S95076

Nevens F, Reheul D (2002) The nitrogen- and non-nitrogencontribution effect of ploughed grass leys on the following arable forage crops: determination and optimum use. Eur J Agron 16:57-74. https://doi.org/10.1016/S11610301(01)00115-0

Pan G, Smith P, Pan W (2009) The role of soil organic matter in maintaining the productivity and yield stability of cereals in China. Agric Ecosyst Environ 129:344-348. https://doi. org/10.1016/j.agee.2008.10.008

Pituello C, Polese R, Morari F, Berti A (2016) Outcomes from a long-term study on crop residue effects on plant yield and nitrogen use efficiency in contrasting soils. Eur J Agron 77:179-187. https://doi.org/10.1016/j.eja.2015.11.027
Poeplau C, Reiter L, Berti A, Kätterer T (2017) Qualitative and quantitative response of soil organic carbon to 40 years of crop residue incorporation under contrasting nitrogen fertilisation regimes. Soil Res 55:1-9. https://doi.org/10. 1071/SR15377

Russell EW (1977) The role of organic matter in soil fertility. Philos Trans R Soc B Biol Sci 281:209-219. https://doi. org/10.1098/rstb.1977.0134

Schjønning P, Jensen JL, Bruun S et al (2018) The role of soil organic matter for maintaining crop yields: evidence for a renewed conceptual basis. Adv Agron 150:35-79. https:// doi.org/10.1016/bs.agron.2018.03.001

Schmidt MWI, Torn MS, Abiven S, Dittmar T, Guggenberger G, Janssens IA, Kleber M, Kögel-Knabner I, Lehmann J, Manning DAC, Nannipieri P, Rasse DP, Weiner S, Trumbore SE (2011) Persistence of soil organic matter as an ecosystem property. Nature 478:49-56

Soane BD (1990) The role of organic matter in soil compactibility: a review of some practical aspects. Soil Tillage Res 16:179-201. https://doi.org/10.1016/01671987(90)90029-D

Sutton R, Sposito G (2005) Molecular structure in soil humic substances: the new view. Environ Sci Technol 39:9009-9015. https://doi.org/10.1021/es050778q

Vos J (1997) The nitrogen response of potato (Solanum tuberosum L.) in the field: nitrogen uptake and yield, harvest index and nitrogen concentration. Potato Res 40:237-248. https://doi.org/10.1007/BF02358249

Wei W, Yan Y, Cao J et al (2016) Effects of combined application of organic amendments and fertilizers on crop yield and soil organic matter: an integrated analysis of long-term experiments. Agric Ecosyst Environ 225:86-92. https:// doi.org/10.1016/j.agee.2016.04.004

Publisher's Note Springer Nature remains neutral with regard to jurisdictional claims in published maps and institutional affiliations. 